\title{
NOTAS SOBRE PLATEROS LIMEÑOS DE LOS SIGLOS XVI-XVII (1535-1639)
}

\author{
por M. ${ }^{a}$ DEl CaRmen HeREdia MORENO
}

\begin{abstract}
El resultado de las investigaciones en los diferentes archivos nacionales y extranjeros, así como de la bibliografía existente al respecto, en la que la autora ya se inició hace algunos años, ha dado como resultado el conocimiento de gran cantidad de datos sobre los plateros que trabajaron en la ciudad de Lima en las fechas indicadas. Asimismo su tipo de trabajo, sus relaciones sociales, la legislación por la que se regían, y el tipo de obras que realizaban son aspectos que se tratan en el trabajo.
\end{abstract}

A number of years spent researching in various national and foreign archives, and in bibliographical sources, has brought to light a large store of information on the silversmitns who worked in the city of Lima in the afore-mentioned period. Their work, their social circumstances, the legislation to which they were subject and the types of work they executed are other aspects dealt with in this study.

El interés de la platería peruana de época virreinal está hoy día suficientemente demostrado a través de la cantidad y calidad de las piezas labradas que han llegado hasta nosotros en su mismo lugar de origen o repartidas por diferentes ciudades españolas y que la investigación reciente está poniendo al descubierto $^{1}$. Dentro del Virreinato, la platería limeña debió jugar un papel preponderante como lo atestiguan los objetos conocidos de esta procedencia, pero casi todos ellos son piezas barrocas o más tardías, labradas desde mediados del siglo XVII en adelante. Mucho menos se sabe de la plata y plateros de Lima antes de estos años, si bien las pocas noticias dispersas con las que contamos son lo bastante elocuentes como para aventurar una panorámica del

1. A manera de síntesis y sin ánimo de ser exhaustivos, pueden consultarse las obras de Lavalle, J.A.: Platería virreynal, Lima, 1974, Rivera, A.L. y Schenone, H.: Platería suramericana de los siglos XVII al XX, Hermer Verlag Muchen, 1981 y Trois siècles d'orfèvrerie Hispano-Americaine, París, 1986, Esteras Martín, E.: Orfebrería hispanoamericana, s. XVI-XIX, Madrid, 1986 y Heredia Moreno, M.C.: Problemática de la orfebrería peruana en España. Ensayo de una tipología, «Príncipe de Viana», 1985, n. ${ }^{\circ} 175$, págs. 339-358 o Ejemplos de mecenazgo indiano en la capilla de San Fermín de Pamplona, *Anuario de Estudios Americanos», 1989, T. XLVI, págs. 409-421. 
papel que los plateros limeños desempeñaron y de la actividad que desarrollaron en la Ciudad de los Reyes desde el momento mismo de su fundación en el año $1535^{2}$.

A partir de esta fecha comienzan a establecerse en la capital del virreinato plateros procedentes de la Península o de algunos de sus dominios europeos. Entre estos últimos se cuentan Elvín de Amberes o Pedro Rudolf, natural de Dunkerque, ambos con tienda abierta en Lima en el año 1550, a Theodor Gerard, de Lübeck, o a Hernán de Colonia, vecinos de Lima en el últio tercio del siglo XVI, y a Miguel de Obermolen que llegó años más tarde, en el 1639, en el séquito del virrey marqués de Mancera ${ }^{3}$.

Llegados de la Península o de procedencia desconocida están documentados en Lima Francisco de Aguilar, de origen cordobés, desde el año $1555^{4}$, Pedro de Llanos en $1557^{5}$, Miguel Morzillo, Pedro de Peña y Juan Ruiz antes de 1568 y entre 1577-1578 , Alonso de Carrión en 1597, Diego de Ledesma en fecha incierta del siglo XVI, Pedro Martín de Leguisano en 1630 y Ruiz Barragán en $1633^{7}$. Este último, junto con otros dieciseis maestros más firma en el año 1597 las constituciones de la Cofradía de San Eloy y Nuestra Señora de la Misericordia, instituida en el convento de San Agustín con fines benéfico-religiosos. Sus nombres, por orden de aparición son, además del propio Barragán, Diego de Requena, Pedro Negrillo, Miguel Bonifaz, Domingo Marroquí de la Concha, Cristóbal Sánchez, Francisco de Riva de nedia (sic), Francisco Juárez, Rodrigo de Aguilar, Bartolomé González Bravo, Jorge de Matos, Juan de Pineda, Pedro Fernández, Jerónimo de Oliva, Francisco Muñoz, Juan Antonio Ro Dávila y Lázaro Nieto ${ }^{8}$. Todos ellos suman un total de treinta artífices plateros conocidos en la Ciudad de los Reyes entre 1534 y 1639. A este número habría que añadir los nombres de otros maestros que, procedentes de La Península, marcharon al Perú sin indicar su destino concreto, algunos de los cuales, sin duda, se establecerían también en la capital del Virreinato, importante centro de atracción para artistas y artesanos de todo tipo ${ }^{9}$. Pero incluso contando con estos últimos e incluso añadiendo los alrededor de treinta nuevos nombres de artífices que aportaremos a lo largo de este trabajo, la cifra debe ser tan sólo una ínfima parte de los maestros plateros

2. Durán Montero, M.A.: Fundación de ciudades en el Perú durante el siglo XVI, Sevilla, 1978, pág. 85 , cita el acta de fundación, del 18 de enero de 1535 , en la que se le da el nombre de Ciudad de los Reyes.

3. Lavalle, J.A.: Platería..., s/p. y Harth-Terre, E.: Platería y plateros del Perú, Museo Metropolitano de Nueva York, 1968, pág. 4.

4. Catálogo de Pasajeros a Indias durante los siglos XVI-XVII-XVIII, Sevilla, 1940, Vol. III, $\mathrm{n} .^{\circ} 2510$.

5. Torre Revello, J.: Orfebrería colonial en Hispanoamerica y particularmente en Buenos Aires, Buenos Aires, 1945, pág. 57.

6. Harth-Terre, E.: Artifices en el virreinato del Perú, Lima, 1945, págs. 52-55.

7. Torre Revello, J.: Orfebrería..., pág. 57-58.

8. Torre Revello, J.: El gremio de plateros en las Indias occidentales, Buenos Aires, 1932, apéndice n. ${ }^{\circ} 8$ reproduce el texto completo de las constituciones de la cofradía.

9. El Catálogo de Pasajeros..., cita muchos nombres al respecto. 
que trabajaron en Lima durante este amplio período de tiempo, porque, únicamente con las ochenta tiendas de platerías que, según algunos autores, existían en la ciudad a comienzos del siglo XVII tendríamos ya un número muy superior al descrito para todo un siglo ${ }^{10}$.

Por otra parte, el emplazamiento de los plateros en lugares privilegiados del centro urbano, los encargos de los que tenemos noticias y su brillante participación en determinados festejos y ceremonias, tanto civiles como religiosas, avalan también el alto nivel de estos artífices a lo largo de todo este período. En efecto, se sabe por declaración de Fray Blas de Atienza que los plateros Diego Rodríguez, zamorano establecido en Lima en 1562 y tallador de la Casa de la Moneda en 1577 por provisión del virrey Toledo, y Lucas Rodríguez, natural de Ciudad Rodrigo y muerto en el año 1585, fundaron la cofradía de San Eloy hacia 1570 en la iglesia de Ntra. Sra. de la Merced, frente a la cual habían abierto tienda algunos plateros como Faxardo, en 1556, el indio Alonso Hernández, apodado el mexicano, o Luis de Ayala que se documenta en el año $1573^{11}$. Poco después, por mandato del virrey Martín Henríquez, se reunieron en la calle de la Platería ${ }^{12}$ que abarcaba la de los plateros de San Agustín, plateros de San Pedro y el callejón de los Clérigos o de los Plateros, entre los conventos de la Compañía de Jesús y el de San Agustín. A este último se trasladó la cofradía de San Eloy en el año 1597, a causa de las obras iniciadas en La Merced, y compró una capilla frontera a la del Cristo de Burgos en precio de diez mil pesos a pagar en cuatro años ${ }^{13}$; allí se reunían para celebrar sus cultos y recibían sepultura los hermanos cofrades. Se sabe, por ejemplo, que en las honras fúnebres de Antonio Ruiz Barragán, celebradas el dieciocho de junio de 1633, predicó el obispo de Tucumán, Melchor de Maldonado y Saavedra ${ }^{14}$.

Distintas fuentes nos informan también de la participaicón de los plateros en actos públicos de diversa índole, como las fiestas de la propia hermandad, nacimientos de los infantes, entradas de los virreyes, etc., en los que, según la tradición, se llegaba a cubrir las calles con baldosas de plata ${ }^{15}$. Un ejemplo

10. Torre Revello, J.: El gremio de plateros..., pág. 20.

11. Harth-Terre, E.: Prólogo al libro de índices de los Cabildos de Lima, Lima, 1946, XLIV y LXII, nota 24 y Platería y plateros del Perú, Nueva York, 1968, pág. 5.

12. Ordenanzas de los plateros limeños del año 1633, en prensa. En el año 1633 se les ordena expresamente agruparse en la calle de la Platería, pero, en realidad, se habían establecido allí desde el siglo XVI según Harth-Terre, E.: Platería y plateros..., pág. 5.

13. Este convento de San Agustín, que fue el segundo asentamiento de los agustinos en la Ciudad de los Reyes, comenz6 a edificarlo fray Miguel de Carmona en unos solares cercanos a la plaza mayor, cedidos por el fraile y pintor Juan de Illescas, lo continuó el obispo de Quito, fray Luis López, en el año 1590, y fue reformado sustancialmente en el siglo XVII. Respecto al convento de la Merced, primera sede de la cofradía de San Eloy, debe tratarse del convento de San Miguel, cuya iglesia construyeron los frailes mercedarios en Lima en el año 1542, dotándola entre 1591-1592 de portada —que ejecutó Cristóbal Gómez- y claustro. El conjunto también fue reedificado en el siglo XVII. (Vid. Bernales Ballesteros, J.: Lima. La ciudad y sus monumentos, Lima, 1972, pág. 61 y 56).

14. Torre Revello, J.: La orfebrería colonial..., pág. 58.

15. Cossio del Pomar, F.: Arte del Perú colonial, Buenos Aires, 1958, pág. 236, recoge la noticia de 
significativo puede ser el de las fiestas celebradas en el año 1630 con motivo del nacimiento del príncipe Baltasar Carlos, ocasión para la que los plateros dispusieron seis carros alegóricos, ricamente ataviados, y organizaron una corrida de toros donde ofrecieron valiosos objetos de plata como premios. El acontecimiento, bruscamente interrumpido por el terremoto que asoló la ciudad de Lima momentos antes de iniciarse el festejo, se reanudó pocos días más tarde y, como colofón, los cofrades de San Eloy celebraron una solemne procesión de acción de gracias por la milagrosa intervención celestial que había impedido desastres mayores. Naturalmente, el suceso fue glosado en prosa y en verso por testigos presenciales que detallan de manera minuciosa el esplendor que desplegaron los plateros limeños ${ }^{16}$. Además, algunos de estos artífices ocuparon puestos destacados en la milicia, como el platero Diego de Fonseca, soldado de la conquista que tuvo repartimiento de indios por cédula de Vaca de Castro en el año 1547. Asimimo se conoce que tenían compañía propia organizada igual que los soldados del virrey y que participaban en las campañas militares, desfiles y paradas castrenses. De otros maestros, como Francisco de Morales, se conocen sus aficiones literarias ${ }^{17}$.

En cuanto a los trabajos de carácter oficial encomendados a estos artífices, puede citarse la fundición del balaustre y la sobretaza con sus mascarones y sus caños de la fuente de la plaza mayor de Lima - la primera con que contó la ciudad, hoy desaparecida-, decorada con las armas del municipio y del virrey don Francisco de Toledo. Esta obra fue encomendada a los plateros Miguel Morzillo y Juan Ruiz en el año 1577, en precio de cuatrocientos quince pesos de plata corriente $y$, poco después, los mismos maestros se encargaron también de fundir las dieciseis «pileas» para sujetar las cadenas que rodeaban la alberca de la fuente, en precio de doscientos pesos de plata de nueve reales ${ }^{18}$.

A todas estas noticias aportadas por diversos historiadores, añadimos ahora un importante conjunto de documentos inéditos extraidos de los Libros de Cabildos de la ciudad, que vienen a reforzar la tesis, antes enunciada, del importante papel que los plateros limeños desempeñaron entre $1535-1639^{19}$. De-

que los comerciantes de Lima en el año 1682 pavimentaron con lingotes de plata de doscientos marcos las calles de la Merced y de los Mercaderes con motivo de la entrada del virrey duque de la Palata. Es posible que esta costumbre proveniese de tiempo atrás.

16. Entre ellos Rodrigo de Carvajal y Robles: Fiestas de Lima por el nacimiento del príncipe Baltasar Carlos, Lima, 1632, reeditada con prólogo de F. López Estrada enSevilla, 1950 (está escrito en silvas y la n. $^{\circ}$ siete corresponde a los plateros) y José Antonio Suardo: Diario de Lima (1629-34), Lima, 1935, págs. 98-102 (recogida por Torre Revello, J.: La orfebrería colonial, págs. 59-63).

17. Harth-Terre, E.: Platería y plateros..., pág. 6.

18. Harth-Terre, E.: Artifices..., págs. 54-55.

19. La primera fecha es la de la fundación de la ciudad y la segunda viene impuesta por la documentación que hemos podido manejar en los Libros de Cabildos de Lima. Hay que tener en cuenta, además, que la serie cronológica de documentos no está completa, porque faltan los libros II (años 1540-43), VII (1562-74), IX (1579-97), y XVI-XIX (1610-1624), lo que explica las lagunas que aparecen en el texto en ciertas fechas. De los libros restantes, es decir, los que hemos consultado, los $n .^{\text {os }}$ I, III, IV, V, VI y 
jamos a un lado, de momento, los aspectos puramente corporativos plasmados en las Ordenanzas de 1633 , que hemos estudiado paralelamente y son objeto de otra publicación ${ }^{20}$. Ahora nos vamos a ocupar, sobre todo, de las relaciones entre los plateros y las autoridades municipales o del gobierno central a través de las noticias sobre ciertos cargos u oficios de control desempeñados por los orfebres, tales como fieles, contrastes, marcadores y ensayadores, entre otros. Pero, tanto en Lima como en los restantes centros plateros del Mundo Hispánico, todos estos títulos se prestan a confusiones y ambigüedades diversas. El problema es bastante grave porque, en muchos casos, no se trata de simples interferencias de nomenclatura sino de ambigüedades de contenido, ya que un mismo término puede aludir a funciones diferentes, según la fecha en que se considere y, a su vez, distintas denominaciones pueden referirse a una misma actividad, según los casos. Por todo ello vamos a tratar de clarificar en lo posible este panorama partiendo de los datos suministrados por la propia documentación.

Las primeras noticias sobre pesos y medidas en Lima datan de las ordenanzas municipales de 1534 que mandan sellarlas por el «diputado» con el sello de la ciudad bajo multa de medio marco de oro. Poco después, en el año 1537 se reitera la obligación de sellar las pesas, las penas por el incumplimiento de la norma - veinticinco pesos de oro- y el precio que ha de cobrar por su trabajo «la persona que echare el sello», el cual se fija en un tomín de oro $^{21}$.Pero, por estos, años estas funciones se incluían entre las responsabilidades de los fieles ejecutores o contrastes ejecutores, nombrados por el municipio para vigilar el cumplimiento de las ordenanzas de la ciudad y castigar las infracciones con las penas previstas ${ }^{22}$ y los términos fiel o contraste no tienen ninguna vinculación directa con el Arte de la Platería.

Sólo a partir del año 1538 comienzan a regularse ciertas normas que afectan a determinados cargos desempeñados específicamente por los plateros. En efecto, en esta fecha se presenta y se acata en el cabildo de Lima una Real Provisión que declara que «el oficio de ensayador de Nueva España y otras provincias de las Indias es anejo al oficio de fundidor y marcador mayor» y se menciona que, hasta el momento, está sin reglamentar en Lima el precio de cada ensaye ${ }^{23}$. Esto significa, por una parte, que se unifican tres oficios

VIII fueron descifrados y anotados por D. Bertrán T. Lee y publicados en Lima en el año 1935; Juan Bromley descifró y anotó los n. ${ }^{\text {os }}$ XIII (Lima, 1944), XIV (Lima, 1945), XV (Lima, 1947), XX (Lima, 1962), XXI-XXII (Lima, 1963) y XXIII (Lima, 1964).

20. Heredia Moreno, M.C.: Ordenanzas..., en prensa.

21. Libros de Cabildos de Lima (en adelante L.C.L.), I, págs. 35 y 187.

22. L.C.L., I, pág. 64. Dicho cargo lo ostenta Diego de Cantillana, fiel hasta el cinco de diciembre de 1534 en que se nombra a Diego Díaz Lucero, fiel contraste ejecutor. A este último le sucede Cristóbal de Melgar, fiel de la ciudad, en junio de 1535 (L.C.L., I, pág. 66). Como ejemplo de sus cometidos, el veintiseis de junio se ordena que ningún vecino, ni oficial ni mercader, eche basura en las calles excepto en los lugares que el fiel mande.

23. L.C.L., I, pág. 215, estos datos ya los había recogido Márquez Miranda, Artífices de la platería en el Buenos Aires colonial, Buenos Aires, 1933, pág. 59. 
distintos aunque relacionados — fundir ${ }^{24}$, ensayar y marcar-, en un mismo sujeto y, por otra, se da a entender que ya existía ensayador mayor en la ciudad aunque no estuviera regulado la cantidad que había de cobrar por su trabajo. De hecho, sabemos que el platero Hernando Bueno ocupó el cargo antes de $1538^{25}$. Ignoramos si el ensayador mayor tiene alguna conexión en estos momentos con la Casa de la Moneda, que en Lima existía desde el año $1535^{26}$, pero a finales del siglo XVI algunos oficiales de dicha institución se reclutarían entre los plateros de oficio. Tal es el caso de Diego Rodríguez, platero de oro, nombrado tallador de la Casa de la Moneda de Lima en el 1577 y del fundidor Diego Enrique ${ }^{27}$.

De cualquier forma, en mayo de 1538 es la primera vez que en las sesiones del cabildo se alude al cargo de ensayador mayor y a la persona que lo ostenta en esos momentos, el platero Diego Bravo. Cuatro meses después, el veintiseis de septiembre de 1538 , el cabildo fija la cantidad de material que se había de ensayar de cada pieza y el precio de cada ensaye: dos tomines y peso y medio, para el oro, y un peso y un ducado, para la plata ${ }^{28}$. Poco después, el cinco de noviembre se ordena que el ensayador mayor selle las piezas ensayadas con marca de ley y marca personal sin percibir cantidad alguna por estas operaciones $^{29}$. Por tanto, se puede afirmar que en el año 1538 , además de la

24. El Catálogo de Pasajeros..., vol. III, pág. 197, n. ${ }^{\circ} 2714$, recoge el nombre de los hermanos valencianos Jaime de Salazar, platero de fundiciones, y Pedro de Salazar, fundidor de oro, que emigran al Perú en el año 1555.

25. Harth-Terre, E.: Plateria..., pág. 3.

26. Durante los siglos XVI-XVII, en la Casa de la Moneda de Sevilla las funciones del ensayador y el fundidor estaban estrechamente relacionadas. Vid. Pérez Sindreu, F. de P.: Operaciones que se realizaban en la Casa de la Moneda de Sevilla desde la entrada de los metales hasta su transformación en moneda, en «Exposición conmemorativa, 400 aniversario de la Casa de la Moneda de Sevilla», Sevilla, 1987. pág. 57.

27. L.C.L., VIII, pág. 475. En esta misma ocasión se procede al nombramiento de otros oficiales, entre ellos tres acuñadores - Joan Simón, Diego Fernández y Manuel Alvarez- que, quizás estén relacionados también con la corporación de plateros. Más adelante, en la pág. 492 se detallan las funciones, sistema de elección y nombramiento del tallador, hecho por el virrey Francisco de Toledo: «...una persona hábil y suficiente en el oficio de los plateros, para que esta persona y no otra alguna abra ni pueda abrir los cuños, tallas y contramarcas y las demás herramientas necesarias para la dicha casa para la labor de la moneda que en ella se hubiere de hacer y labrar, y para este efecto, habiendo cometido a los oficiales reales de la Real Hacienda de esta ciudad se informasen cual de los plateros de oro que al presente hay en esta... sería más hábil y suficiente y de confianza para servir el dicho oficio de tallador y... habiendo traido los dichos oficiales ante mí cantidd de muestras de obras hechas por algunos de los plateros y relación de sus habilidades, suficiencia y confianza, y hecho el examen necesario de ello, pareció que vos, Diego Rodríguez, érades persona hábil... para usar dicho oficio...». Según Harth-Terre, E.: Prólogo al libro de Indices..., pág. XLII, nota 24, Diego Rodríguez ya era tallador de la Casa de la Moneda en el año 1575. Si ello fuera cierto, hemos de suponer que el nombramiento de 1577 fue una reelección.

28. L.C.L., I, pág. 245. Se reiteran las cantidades del ensaye y los precios correspondientes el 1 de agosto de 1539 (L.C.L., I, pág. 353) al informarse el Cabildo que Diego Bravo cobra abusivamente por su trabajo.

29. L.C.L., I, pág. 252. «...se notifica al ensayador de esta ciudad que toda la plata que ensayare le eche la ley que tiene con punzón toda la ley que tuviere, sin sacar nada, y le ponga por letras por punzón y ponga su contramarca señalada para que se vea quién la ensayó... bajo pena de cincuenta castellanos...n. 
fundición, en cumplimiento de la Real Provisión de este año, los oficios de ensayar y marcar coincidían en un mismo sujeto, si bien queda claro se trataba de operaciones distintas y sólo podía cobrarse el ensaye. Se fija también en esta fecha la obligación de estampar en las piezas dos marcas - de ley y personal-.

Más adelante, en el año 1544, ante las continuas protestas de los ciudadanos por los fraudes en todo tipo de pesas y pesos, el cabildo acuerda nombrar un fiel platero que vigile y sancione los pesos faltos ${ }^{30}$. La denominación que se utilizará específicamente durante muchos años será la de «fiel de pesos (y pesas)» ${ }^{31}$ y se aplica por primera vez al platero Juan de Bruselas a quien el veinticinco de mayo de 1549 el cabildo ordena que vea los marcos y pesas de hierro y otros metales y les eche por sello una estrella con las armas de la ciudad y su propio nombre ${ }^{32}$. El cabildo encarga también a Juan de Bruselas hacer un sello del tamaño de un real para herrar los paños y otro sello grande de plata para autentificar los documentos oficiales. Ambos sellos los hizo Bruselas tra ser elegido su dibujo preliminar entre otros varios ejecutados por diferentes artíficiles locales ${ }^{33}$. De todo ello se deduce que la misión del fiel de pesos a mediados del siglo XVI, independientemente de los encargos y pagos que podía percibir como maestro platero, se resumían en comprobar la exactitud de los pesos y pesas de cualquier índole y en sellarlos con las armas de la ciudad y con su nombre. Es decir, funciones que años antes no entraban en las competencias específicas de los plateros sino más bien entre las de los fieles ejecutores, se transfieren a partir de 1544 al campo de la platería, aunque por designación expresa del municipio. Además, el cargo de fiel de pesos, designado por el cabildo de la ciudad, era compatible con otros oficios parecidos. El propio Juan de Bruselas simultaneó el fielazgo de pesos con el cargo de veedor de los plateros desde el veinte de septiembre de 1549 hasta el tres de abril de 1551 en que dimitió para marcharse a Charcas. En esta última fecha se le denomina también ensayador de la ciudad, lo que supone la acumulación de responsabilidades y de diversas funciones de control en una misma persona por cuenta de organismos diversos - la ciudad y la corporación-34. Por otra parte, el nombramiento de veedor de Juan de Bruselas se produce tan sólo ochos meses después de la designación del platero portugués

30. L.C.L., III, pág. 89.

31. L.C.L., IV, pág. 192. Se nombra fiel de medidas a Juan Esteban; este cargo es independiente, casi siempre, del de fiel de pesos y no suele recaer en ningún platero de oficio.

32. L.C.L., IV, pág. 110 (Veintiuno de mayo de 1549).

33. L.C.L., IV, págs. 91, 128, 139, 165. A este sello se añadió otro nuevo el veintidós de diciembre del año 1603 en que «...se hizo» otro mediano con las armas de esta ciudad para sellar cartas y despachar con él muchas cosas, porque con el grande que hay no se podía hacer, por la hechura del cual y plata en que se hizo había dado y pagdo (el alguacil mayor) veinte pesos de a ocho reales (L.C.L., XIV, pág. 589).

34. L.C.L., IV, pág. 177, 180, 240, 363. Además en el año 1561 el Cabildo establece el nombramiento anual de veedores (L.C.L., VI, pág. 416), bajo pena de cincuenta pesos para obras públicas. 
Antón Rodríguez para ocupar dicho puesto, una vez que el cabildo de Lima acababa de establecer la normativa a seguir para nombramientos de alcaldes y veedores en todos los gremios artesanos locales ${ }^{35}$.

Tras la partida de Juan de Bruselas el fielazgo de pesos recayó en el platero y ensayador Mateo de Ortega ${ }^{36}$, a quien «...le hacían la dicha merced con cargo que tenga el contraste desta ciudad». En la correspondiente acta de nombramiento de contraste se detallan y concretan sus funciones en «...que sea obligado a pesar y hacer la cuenta de plata y oro que se le llevare y a ver si es buena o no de recibir y dar cédulas dello a sus dueños por todo lo cual lleve de derechos a las personas que ante él quisieren ir y pesar y hacer cuenta y saber si la dicha plata o oro es de recibir o no, dos tomines de cada cien pesos...» ${ }^{37}$. Se trata, en suma, de pesar, contar, comprobar y certificar la ley de los metales nobles, no de las pesas y pesos - como era también oficio de su competencia al estar designado simultáneamente como ensayador-. Por lo tanto, observamos aquí, en el año 1551 , nuevas responsabilidades de fiscalización añadidas a las anteriores y reunidas en un mismo platero que, por estos años y por esta acumulación de cargos, debió ser sujeto importante en el contexto de la corporación local. No queda claro en el acta de contraste si el «dar cédulas dello» se refiere a la impresión de alguna marca-que sería, sin duda, la de la ciudad- sobre los metales analizados. Si esto fuera así, cabría pensar que, a lo mejor, sólo existía un único punzón de la ciudad y que, al tener que utilizarlo tanto para sellar pesas como metales nobles, resultaba más cómodo y más segura centralizar ambas operaciones en un sólo maestro de confianza, a quien el cabildo, previamente, había hecho depositario del mismo.

Pero esta situación sufre continuas alteraciones. Diego de Flores ostenta también el cargo de ensayador cuando el once de noviembre de 1556 se le nombra fiel de las pesas ${ }^{38}$. Al año siguiente se reitera la obligación de sellar las pesas con la marca de la ciudad y se ordena ajustar su peso cada cuatro meses $^{39}$. Pero a partir de aquí y durante varios años los fieles de pesas que

35. L.C.L., IV, pág. 58. Ibidem, pág. 55 el Cabildo de Lima, el veinte de enero de 1549 establece el procedimiento a seguir por todos los oficios para nombrar sus cargos. Cada gremio había de proponer a cuatro maestros examinados entre los que el Cabildo elegiría a dos, uno para alcalde y otro para veedor. Ello supone una intromisión del municipo en los asuntos internos de los gremios para controlarlos en la medida de lo posible. En el caso de los plateros la elección recayó en los portugueses Francisco Rodríguez, como alcalde, y Antón Rodríguez, como veedor (pág. 58) que juraron sus cargos el ocho de febrero siguiente (pág. 70). Años después, en el 1637 ya se establece diferencia entre el alcalde de plata, título que recae en Miguel Bonifaz y alcalde oro para el que se nombra a Antonio de Hergueta (L.C.L., XXIII, pág. 424).

36. Catálogo de Pasajeros..., vol. III, pág. 178, n. ${ }^{\circ}$ 2.521. Platero vecino de Lima, natural de Valdearenas, hijo de Francisco de Sigüenza y de María Ortega. En el 1555 pasa al Perú con su mujer, un hijo y Francisca Ortiz, hija de Francisco de Villoldo y de María Ortiz.

37. L.C.L., IV, pág. 363.

38. L.C.L., V, pág. 526.

39. L.C.L., VI, el veinte de diciembre de 1557. 
se suceden -Francisco Pérez en 1560, Juan Sánchez Pechalero en el 1561 y Juan Pérez pocos meses después por la marcha del anterior a Trujillo- se mencionan como simples plateros sin ningún otro título, aparte del propio fielazgo ${ }^{40}$.

Un nuevo cambio de nomenclatura se produce cuando en la sesión del ayuntamiento del diez de enero de 1575 se comienza nombrando a Ginés Martínez como fiel de pesos interino, hasta tanto se rematara el oficio tras los correspondientes pregones, y se concluye con el nombramiento del mismo artífice platero como «fiel para marcar la plata que se labrare este año». A este respecto se le indica expresamente su obligación de comprobar en las piezas la ley en vigor de once dineros y cuatro granos, cobrando los derechos correspondientes, y la de marcar las piezas legales con su marca personal y la de la ciudad ${ }^{41}$. Ginés Martínez fue reelegido para el puesto de fiel de pesos hasta el año 1578 inclusive $^{42}$, pero no se le vuelve a denominar marcador de plata labrada; por lo que desconocemos si continuó simultaneando este oficio con el anterior: De cualquier forma, estas funciones del marcador de plata labrada son semejantes a las que en el año 1539 desempeñaba el ensayador mayor. Las diferencias, aparte de la marca de ley que estampaba este último en lugar de la de la ciudad que ponía aquél, estriban en el sistema de nombramiento de ambos cargos y en que cada uno representa a una autoridad concreta; al fiel para marcar la plata labrada lo designaba el cabildo -igual que al fiel de pesos-, es decir, la autoridad municipal, y al ensayador mayor lo nombraba el virrey o, lo que es lo mismo, el poder central, a quien representa.

Por otra parte, al no disponer de ningún dato sobre la existencia de ensayador mayor desde los tiempos de Juan Bravo, cabría la posibilidad de que este cargo hubiese caido en desuso en el año 1577, sustituido por el de mar-

40. L.C.L., VI, págs. 348, 416 y 462 . Hay que tener en cuenta, sin embargo, que falta el L.C.L., VII, correspondiente a los años 1562-74.

41. L.C.L., VIII, pág. 51. La obligatoriedad de la marca de artífice, por el contrario, no se regula hasta el veintiocho de enero de 1630 (L.C.L., XXI, pág. 223). «...se trató que es conveniente y necesario que los plateros de mazonería pongan cada uno marca la que eligieren en cada una pieza de plata que labraren para que se sepa y entienda el maestro que la labró, porque de esta manera cesarán muchos inconvenientes que pueden resultar. $Y$ tratado y conferido sobre ello se mandó que todos los plateros de mazonería, dentro de seis días de como se pregonare, elija cada uno la marca y señal que quisiere y la traiga ante el escribano del cabildo, el cual, en un libro que para ello tenga, la asiente y ponga en él, la cual dicha señal y marca pongan en cada una de las dichas piezas que labraren y no las tengan ni vendan en sus tiendas si no fuese con la dicha señal, so pena de perdimiento de las dichas piezas de plata que estando acabadas estuvieren sin la dicha marca o se vendieren sin ella, aplicadas para la Cámara de su Majestad la mitad y la otra mitad para obras públicas, juez y denunciador por iguales partes y de seis días de cárcel, y para ello se pregone lo susodicho en la plaza pública y calle de la Platería de esta ciudad...». Más adelante, las Ordenanzas de los ensayadores del Perú, de 1649-1651, en su capítulo veinticinco insistirán en este punto al ordenar que cada platero ha de tener su «marca particular» para marcar las piezas que labrare. (Vid. Recopilación de Leyes de los Reinos de Indias. Mandadas imprimir y publicar por la Majestad Católica del Rey Don Carlos III Nuestro Señor, Madrid, 1681, libro IV, título XXII, ley XVII. Hemos manejado la reedición de Cultura Hispánica, Madrid, 1973, tomo II).

42. L.C.L., VIII, págs. 163, 359-60 y 557. 
cador, lo que, en definitiva, vendría a suponer un incremento de la autonomía y poder del municipio frente al gobierno central ${ }^{43}$. También es posible $-s i$ continuaba en vigor la Real Provisión de 1538 - que el oficio de ensayador mayor se identificase en estos momentos con el de fundidor o con el de ensayador de la Casa de la Moneda que, precisamente el veintitrés de septiembre de 1577 acababa de recaer en los plateros Diego Enrique y Diego de la Torre, respectivamente, por mandato expreso del virrey Toledo $^{44}$. En este último caso, a nuestro juicio el más probable, nos encontraríamos con dos cargos paralelos y simultáneos que representaban al gobierno municipal - fiel para marcar la plata labrada - y a la administración central - ensayador mayory que, precisamente por ello estarían separados en dos artífices distintos, si bien el primero había de estar sujeto al segundo por la mayor categoría de . este último ${ }^{45}$.

A finales del siglo XVI tiene lugar un pleito entre el platero Jacome Bricanino, fiel de pesos y medidas desde antes de 1598 y hasta 1600 inclusive $^{46}$, por una parte, y el mestizo Gregorio Moxica, de la otra, por el arrendamiento del fielazgo correspondiente al año 1598. El arriendo estaba fijado en ciento treinta pesos que pagaba el platero, pero Moxica hace una oferta más ventajosa para conseguirlo. El pleito origina toda serie de consideraciones esgrimiéndose, a favor o en contra de ambas partes litigantes, desde la mesticidad de Moxica, «persona de quien no se puede fiar cosa de tanto peso», hasta el origen extranjero de Bricanino que lo inhabilitaría para el puesto o hasta la ilegalidad del hecho del propio arriendo. Como colofón y desde el punto de vista que nos interesa, se declara que el oficio de fiel si es lícito arrendarlo

43. A mediados del siglo XVI los plateros Juan de Bruselas, Mateo de Ortega y Diego de Flores se mencionan como «ensayadores de la ciudad», pero, al ignorar sus atribuciones concretas y su sistema de nombramiento, no sabemos si identificarlos con los ensayadores mayores, como Juan Bravo, o con los marcadores, equivalentes a los ensayadores municipales.

44. L.C.L., VIII, pág. 499.

45. Las Ordenanzas de ensayadores del Perú de 1649-51, nos informan de las distintas clases de ensayadores existentes y de otros cargos análogos que estaban bajo la autoridad del ensayador mayor. Al parecer, habían de elegirse dos ensayadores mayores que residieran en la ciudad de Lima, los cuales tenían facultad para visitar a los ensayadores de las Casas de la Moneda, fundiciones (Ensayadores de barras) y asientos de minas, a los marcadores de plata labrada y afinadores de oro, y las tiendas de los plateros, tiradores y batihojas. En estas visitas habían de ensayar $\longrightarrow$ reensayar- las piezas para vigilar la ley de la plata y el oro en barras y tejos, moneda, vajilla y joyas. Entre sus competencias entraban también las de examinar a ensayadores y marcadores e inspeccionar las herramientas de los ensayes (Vid. Recopilación de Leyes de los Reinos de Indias..., tomo II, libro IV, título XXII. Más tarde, las Ordenanzas dadas por Carlos III en el año 1771, ley XXVI, título 3, capítulo 1 vuelven a establecer las diferencias entre los ensayadores mayores y los marcadores municipales al indicar que «el ensayador mayor de la Casa de la Moneda, donde lo hubiere, acompañado de los marcadores públicos... y de los aprobadores o diputados o primeros oficiales de la Congregación, visitarán cuatro o seis veces al año las tiendas y obradores de los plateros...n. (Novísima recopilación de las Leyes de España. Mandadas formar por Carlos IV, Madrid, 1805, libro IX, título X, ley XXVI, pág. 291).

46. A falta del L.C.L., XII, la primera noticia que tenemos al respecto data de nueve de enero de 1598 (L.C.L., XIII, pág. 13) donde se le confirma en el cargo para que lo use «...como hasta aquí lo ha hecho", lo que presupone, al menos, un nombramiento anterior. 
y se refiere tan sólo a «sellar pesos y medidas de los bastimentos», mientras que el «que no se puede arrendar y su majestad manda que no se arriende sino que se nombre persona con salario de los propios es el oficio de contraste que hoy es diferente». Este último cargo recayó por fín en Jácome Bricanino.

Recordemos en este punto que el contraste, a mediados del siglo XVI, era el platero encargado de comprobar la ley de los metales nobles, pesarlos y contarlos, y que estas competencias podían recaer en el mismo platero que ostentase el fielazgo de pesos. Por el contrario, a partir de ahora esta situación comienza a cambiar. Por una parte, fiel de pesos y contraste se diferencian en cuanto a su sistema de remuneración; el fielazgo que se arrienda anualmente al municipio por una cantidad en metálico - el hecho de estar tan solicitado nos hace pensar que se sacarían de él pingües ganancias-, mientras que el contraste recibe un sueldo de los propios por su trabajo. Por otra parte, tanto el fielazgo de pesas como el de medidas, unidos o no, se arriendan a partir de ahora a sujetos de diferentes oficios como herreros, latoneros, carpinteros, etc., a los que, a veces, se les denomina selladores, sobre todo a los de medidas $^{47}$. Sólo esporádicamente, el platero Diego de la Torre, antiguo ensayador de la Casa de la Moneda en el año 1577 y contraste de la ciudad entre el cinco de diciembre de 1603 y el treinta de agosto de 1604 , ostenta también durante algunos meses de 1604 el título de fiel ${ }^{48}$. En esta misma fecha se fija el salario del contraste en cuatrocientos pesos corrientes de nueve reales anuales, a pagar la mitad por el Cabildo, del arrendamiento del fielazgo de pesas y medidas y de los propios, y la otra mitad de los «tributos baços» de la Caja real ${ }^{49}$. A partir de aquí será el propio virrey el que tendrá que aprobar el nombramiento del contraste y éste, a su vez, es obligado a no cobrar a cambio de su trabajo concreto.

A Diego de la Torre sucede en el oficio de contraste el platero de oro Domingo Marroquín de Concha el treinta de agosto de 1604 hasta, al menos, el nueve de octubre de $1609^{50}$. Luego, tras unos años que desconocemos, el tres de enero de 1625 se reelige para este oficio a Miguel de Rojas, platero de oro, que ya lo venía desempeñando con anterioridad y que lo ocupará, al menos, hasta el año 1637, exceptuando el breve paréntesis entre el trece de noviembre de 1626 y el tres de enero de 1628 en que lo sustituye el platero Benito Pereira ${ }^{51}$.

47. L.C.L., XIV, pág. 397, año 1603; XV, pág. 701, año 1604; XX, pág. 580, año 1627, etc.

48. L.C.L., XIV, pág. 578, 85-86 y 846 .

49. L.C.L., XIV, pág. 675.

50. L.C.L., XIV, pág. 846-847, 883, 995 y L.C.L., XV, pág. 242, 494, 670, 896. Estos últimos documentos se refieren a distintos libramientos hechos al platero a cuenta de su salario como contraste. Recordemos que este artífice es uno de los diecisiete que firmaron las constituciones de la cofradía de San Eloy.

51. L.C.L., XX, pág. 25, 260, 296, 423; XXI, págs. 16, 22, 109, 208; XXII, págs. 117, 236 y XXIII, pág. 431. 
La documentación de estos años en que Rojas desempeñó el oficio es interesante para conocer nuevos aspectos sobre el funcionamiento del mismo. Así, por ejemplo, a partir de 1626 las actas de nombramiento repiten siempre el salario estipulado por el virrey el año 1604 junto con la indicación expresa de que el platero no cobre ninguna cantidad aparte por su trabajo diario como contraste, bajo pena de cincuenta pesos la primera vez, cien la segunda y privación del oficio y del salario la tercera ${ }^{52}$. Las mismas fuentes nos informan que la elección del cargo se efectuaba mediante voto secreto y que para desempeñarlo era imprescindible haberse examinado de contraste con anterioridad. Precisamente la elección del tres de enero de 1634 recayó sobre Francisco Muñoz, alcalde de los plateros, que obtuvo once votos frente a los diez de Miguel Rojas, pero el resultado fue recurrido por la falta de examen de aquél. En el largo pleito subsiguiente que, al final, se falla a favor de Rojas tras nombrar a uno y otro platero para ocupar el puesto de manera alternativa, se alega que, además de las razones expuestas, sólo Rojas tenía un título «legal» expedido por el virrey años antes, frente a Francisco Muñoz que poseía un título «ilegal» puesto que le había sido otorgado por el Cabildo ${ }^{53}$. En consecuencia, tras dejar bien claro que el derecho de nombrar contraste corresponde al gobierno central y no a la autoridad municipal, el Cabildo se ve obligado a pagar a Rojas el sueldo completo de la contrastía de todo este período. Una vez más, se pone de manifiesto la participación del poder central en el nombramiento de los contrastes municipales, como venía siendo norma desde el año 1604. Además, el hecho de que por estos años no se cite en la documentación el cargo de marcador municipal nos inclina a pensar que éste se había unido al de contraste, que desempeñaba una función parecida de vigilancia y control, como a veces ocurría en otros centros plateros de la Península $^{54}$.

A continuación, resumiendo todo lo que acabamos de exponer, hacemos una relación de los distintos cargos u oficios según el orden en que aparecen en el texto, indicando el significado concreto de cada uno de ellos en la fecha que se reseña. Después se incorpora también la nómina de los artífices plateros que ocuparon los distintos cargos, por orden cronológico, indicando las fechas en que se mencionan en la documentación. Con estas listas esperamos contribuir a aclarar el significado de los cargos u oficios de la Ciudad de los Reyes a lo largo de todo un siglo - 1535-1639-. La relación es incompleta

52. L.C.L., XX, pág. 427; XXI, págs. 16, 22 y 109; XXII, pág. 117 y 236.

53. L.C.L., XXIII, págs. 17, 33, 174, 298, 311, 342-44, 411 y 431. Años más tarde, en 1649, Felipe IV nombra a Miguel de Rojas ensayador mayor, según se menciona en las Ordenanzas del Perú, recogidas y coordinadas por Thomás de Ballesteros... y nuevamente añadidas en las Ordenanzas que para el nuevo establecimiento del tribunal de la Santa Cruzada ha dispuesto y mandado observar según la Real Intención de S.M. y Bula de N.S.P. Benedicto XIV el Exmo. Sr. D. Joseph Antonio Manso de Velasco... virrey, Gobernador y Capitán General de los Reinos del Perú y Chile, reimpresas en Lima, año 1572, Libro III, título XVII.

54. Sanz Serrano, M.J.: El gremio de plateros sevillano, 1344-1867, en prensa. 
debido a las lagunas cronológicas de la documentación que hemos manejado pero aún así, pueden servir para trazar una panorámica sobre los cargos de control de la platería limeña en su relación con el gobierno central y municipal. Esperemos que pronto pueda completarse la lista de nombres y el contenido de los oficios.

Cargos $u$ oficios. Definición, cronología, atribuciones, etc.

Fiel ejecutor o contraste ejecutor. Entre los años 1534-1537 denomina a la persona o personas que vigilan el cumplimiento de las ordenanzas de la ciudad y castigan a los infractores con las penas previstas. Es posible que, entre sus atribuciones figurase en algún momento la de sellar los pesos y pesas con las armas de la ciudad pero, por estos años, los términos «fiel» y «contraste» no guardan ninguna relación directa con el arte de la platería limeña.

Ensayador Mayor (fundidor o marcador mayor). Por una Real Provisión de 1538 dada para todas las provincias de las Indias, el oficio de ensayador mayor va unido al de fundidor y marcador mayor, lo designa el poder central y sus funciones son ensayar las piezas de plata y oro, y marcarlas con marca de ley y de la ciudad. Este mismo año se fija el precio de cada ensaye y se indica que el marcaje es gratis. El puesto lo ocupa un platero.

Fiel de pesos y pesas. Platero elegido anualmente por el cabildo, a partir del año 1544, para visitar, junto con los diputados de la ciudad, los pesos y pesas y sancionar a los mercaderes que tuvieren pesos faltos. Entre sus funciones se recogen también las de marcar los pesos con marca personal y de la ciudad, así como hacer las matrices de las propias marcas por encargo del municipio. En el año 1557 se ordena que se ajusten las pesas cada cuatro meses. En el 1598 se indica expresamente que el cargo es distinto «hoy» al de contraste, lo que nos hace pensar que antes estuvieron unidos. A partir del año 1604 el fielazgo de pesos se separa de los plateros de oficio y comienza a arrendarse sistemáticamente a sujetos de otras profesiones, a los que se les suele denominar «selladores», al tiempo que el cargo se divide en dos: «lo que toca a carpintería y medidas, en uno, y el de pesos y pesas de hierro, medidas de miel y aceite que suelen ser hojas de lata, en otro» ${ }^{55}$.

Alcaldes y veedores. Autoridades de la corporación de plateros que, a partir del año 1551, son elegidos por el cabildo de la ciudad entre dos artífices propuestos por la corporación para cada cargo, pero sus funciones concretan se fijan expresamente en las Ordenanzas de la Platería del año $1633^{56}$. Por otra parte, ambos puestos eran compatibles con cualquier otra actividad de control como representantes del municipio o del gobierno central.

Contraste municipal. El término, en el año 1551, designa al platero que se encarga de pesar, contar y determinar la bondad de la plata y el oro (posiblemente también de las monedas). Cobra por su trabajo y lo nombra la autoridad municipal. En el año 1598 queda claro su separación del fiel de pesos y

55. L.C.L., XIV, pág. 701.

56. Sobre las Ordenanzas de 1633 vid. nuestro trabajo Ordenanzas..., en prensa. 
en el 1604 el virrey fija su salario asignándose la facultad de aprobar su nombramiento en adelante. Posiblemente a finales de siglo XVI se identifique con el fiel para marcar la plata labrada, término este último que no aparece en la documentación a partir de entonces.

Fiel para marcar la plata labrada (o marcador municipal). A partir del año 1575 el cargo recae en un platero elegido por el Cabildo anualmente. Sus competencias son semejantes a las del ensayador mayor -ensayar y marcar la plata labrada- pero representa al municipio en vez de al gobierno central.

Ensayador de la Casa de la Moneda. En el año 1577, platero que trabaja en dicha institución desempeñando, entre otras, funciones similares a las del ensayador mayor al que, posiblemente, sustituye por estas fechas.

Tallador de la Casa de la Moneda. En 1577, platero encargado en la Casa de la Moneda de abrir cuños, tallas y contramarcas, así como de las herramientas necesarias para el trabajo de la moneda.

Ensayador de la ciudad. En 1551 parece referirse al platero que ocupa el cargo de ensayador municipal que habría que identificar con el que en 1575 se denomina fiel para marcar la plata labrada o marcador municipal. También es posible que aluda al ensayador mayor, aunque esto último nos parece menos probable.

Para terminar, hacemos una breve mención de otros artífices limeños, como los batihojas o los doradores, estrechamente relacionados con los plateros y fundidores. Las ordenanzas de los batihojas fueron aprobadas por el Cabildo de Lima el trece de enero de $1634^{57}$. Entre sus operarios tenemos noticia de Pedro de Hoz, elegido veedor en el año 1634 y 1635 y examinador en el $1636^{58}$, Domingo Martín, cuya mujer consigue licencia en el 1634 para poner tienda tras la muerte de su marido ${ }^{59}$ y Juan López y Juan de Alvear que obtienen sus cartas de examen en el mes de noviembre de $1635^{60}$. Respecto de los doradores, conocemos el caso de dos esclavos negros, Domingo Congo y otro, cuyos amos, el platero de mazonería Fernando de Mesa y el fundidor Luis de Aldana consiguen, tras largos pleitos en 1634-5, licencia para que se les permita trabajar como oficiales a su servicio ${ }^{61}$.

57. L.C.L., XXIII, pág. 26.

58. L.C.L., XXIII, págs. 117-185 y 422.

59. L.C.L., XXIII, pág. 143.

60. L.C.L., XXIII, págs. $274-277$.

61. L.C.L., XXIII, págs. 244, 247, 258 y 261-265. Entre los testigos que presenta Fernando de Mesa a favor de Domingo Congo figuran el platero de oro Miguel de Rojas, por estas fechas contraste de la ciudad, y Juan Sánchez Albarrán, platero de mazonería. 
OFICIOS O CARGOS (NOMINA DE PLATEROS)

\begin{tabular}{|c|c|c|c|c|c|}
\hline Ensayador Mayor & Fiel de pesos(as) & Veedor & Alcalde & Contraste & $\begin{array}{l}\text { Fiel para marcar } \\
\text { Plata labrada } \\
\text { (marcador municipal) }\end{array}$ \\
\hline $\begin{array}{l}\text { Hernando Bueno } \\
\text { (antes de 1538) } \\
\text { Diego Bravo (26-IX- } \\
\text { 1538/1-VIII-1539) }\end{array}$ & & & & & \\
\hline $\begin{array}{l}\text { Ensayador de la ciudad } \\
\text { Juan de Bruselas } \\
(20-I X-1549) \\
\text { Mateo de Ortega } \\
(3-I V-1551)\end{array}$ & $\begin{array}{l}\text { Juan de Bruselas } \\
(25-V-1549 / 3-I V-1551) \\
\text { Mateo de Ortega } \\
\text { (3-IV-1551) }\end{array}$ & $\begin{array}{l}\text { Antón Rodríguez } \\
\text { (29-I-1549) } \\
\text { Juan de Bruselas } \\
\text { (20-IX-1549/3-IV-1551) }\end{array}$ & $\begin{array}{l}\text { Francisco Rodríguez } \\
\text { (29-I-1549) }\end{array}$ & $\begin{array}{l}\text { Mateo de Ortega } \\
(3-I V-1551)\end{array}$ & \\
\hline $\begin{array}{l}\text { Diego de Flores } \\
(11-\mathrm{IX}-1556)\end{array}$ & $\begin{array}{l}\text { Diego de Flores } \\
(11-\mathrm{XI}-1556)\end{array}$ & & & & \\
\hline $\begin{array}{l}\text { Ensayador de la } \\
\text { Casa de la Moneda }\end{array}$ & $\begin{array}{l}\text { Francisco Pérez } \\
\text { (5-VII-1560) } \\
\text { Juan Sánchez Pechalero } \\
\text { (13-I-1561) } \\
\text { Juan Pérez } \\
\text { (22-IX-1561) }\end{array}$ & & & & \\
\hline $\begin{array}{l}\text { D. }^{\circ} \text { de la Torre } \\
(23-\mathrm{IX}-1577)\end{array}$ & $\begin{array}{l}\text { Ginés Martínez } \\
(10-\mathrm{I}-1575 / 10-\mathrm{I}-1578)\end{array}$ & & & & $\begin{array}{l}\text { Ginés Martínez } \\
(10-\mathrm{I}-1575)\end{array}$ \\
\hline $\begin{array}{l}\text { Fundidor de la } \\
\text { Casa de la M. } \\
\text { Diego Enrique } \\
\text { (23-IX-1577) }\end{array}$ & & & & & \\
\hline
\end{tabular}


OFICIOS O CARGOS (NOMINA DE PLATEROS)

\begin{tabular}{|c|c|c|c|c|c|}
\hline Ensayador Mayor & Fiel de pesos(as) & Veedor & Alcalde & Contraste & $\begin{array}{l}\text { Fiel para marcar } \\
\text { Plata labrada } \\
\text { (marcador municipal) }\end{array}$ \\
\hline & $\begin{array}{l}\text { Jácome Bricanino } \\
\text { (Antes de 9-I-1598) }\end{array}$ & & & $\begin{array}{l}\text { Jácome Bricanino } \\
\text { (Antes de 9-I-1598/ } \\
\text { 13-I-1600) }\end{array}$ & \\
\hline & $\begin{array}{l}\text { Diego de la Torre } \\
\text { (1604) }\end{array}$ & & $\begin{array}{l} \\
\text { Francisco Muñoz } \\
\text { (30-I-1634) }\end{array}$ & $\begin{array}{l}\text { Diego de la Torre } \\
\text { (5-XII-1603/ } \\
\text { 30-VIII-1604) } \\
\text { Domingo Marroquín } \\
\text { de Concha (30-VIII- } \\
\text { 1604/9-X-1609) } \\
\text { Miguel de Rojas } \\
\text { (3-V-1625/13-XI-1626) } \\
\text { Benito Pereira } \\
\text { (13-XI-1626/3-I-1628) } \\
\text { Miguel de Rojas } \\
\text { (3-I-1628/30-I-1634) } \\
\text { Francisco Muñoz } \\
\text { (2-I-1635) }\end{array}$ & \\
\hline & & & $\begin{array}{l}\text { Antonio de Hergueta } \\
\text { Platero de oro } \\
\text { (9-XII-1637) } \\
\text { Miguel Bonifaz } \\
\text { (Platero de plata) } \\
\text { (9-II-1637) }\end{array}$ & $\begin{array}{l}\text { Miguel de Rojas } \\
\text { (1-I-1636/2-III-1637) }\end{array}$ & \\
\hline
\end{tabular}

